\title{
Adamantane-based Bidendate Metal Complexes in Crystalline and Solution State
}

\author{
Kazuaki OHARa, ${ }^{* \dagger}$ Masahide Tominaga, ${ }^{*}$ Hyuma Masu, $* *$ Isao AzumaYa, ${ }^{* * *}$ and \\ Kentaro YAMAGUCHI ${ }^{* \dagger}$ \\ *Faculty of Pharmaceutical Sciences at Kagawa Campus, Tokushima Bunri University, 1314-1 Shido, \\ Sanuki, Kagawa 769-2193, Japan \\ **Center for Analytical Instrumentation, Chiba University, 1-33 Yayoi, Inage, Chiba 263-8522, Japan \\ ***Faculty of Pharmaceutical Sciences, Toho University, 2-2-1 Miyama, Funabashi, Chiba 274-8510, Japan
}

\begin{abstract}
Bidentate organic molecules with imidazole or benzimidazole moieties connected to a rigid 1,3-diphenyladamantane spacer are simple and unique building blocks that facilitate the assembly of supramolecular architectures in the solid state via metal-coordination. Single-crystal X-ray analysis revealed that the complexation of bidentate ligand-bearing imidazole moieties with cobalt(II) or cadmium(II) ions in methanol/chloroform produced complexes that showed doublyinterpenetrated two-dimensional (2D) sheets through the formation of coordination bonds between the cobalt or cadmium metal centers and the nitrogen atoms of the imidazole groups. In the complexation of another ligand bearing a bulky benzimidazole group with cobalt(II) ion generated in methanol/chloroform, extended zigzag one-dimensional (1D) chains were formed, indicating that the molecular shape and bulkiness of the ligand design are crucial in the control of coordination polymers. The crystallization solutions were subjected to cold-spray ionization mass spectrometry (CSI-MS), and ion peaks derived from complexes with metal-ligand 1:2 and 1:1 were observed in complexation with ligands bearing the imidazole and benzimidazole moieties, respectively. The metal-ligand ratio in the CSI-MS analysis was identical to that found in the single-crystal X-ray analysis of an independent molecule. In addition, coordination oligomers with large molecular weight were detected as part of the obtained coordination polymers observed by CSI-MS/MS.
\end{abstract}

Keywords Adamantane, bidentate ligand, cold-spray ionization, coordination oligomer

(Received June 13, 2016; Accepted September 5, 2016; Published December 10, 2016)

\section{Introduction}

The design and construction of coordination polymers and networks have attracted significant attention over the last few decades because the polymers possess intriguing structures and topological features as well as interesting chemical and physical properties. $^{1-5} \quad$ Metal-mediated architectures have unique applications as functional crystalline materials in catalysis, ${ }^{6,7}$ guest inclusion, ${ }^{8-15}$ photochemistry ${ }^{16-19}$ and gas storage. ${ }^{20-26}$ The diversity of metal-directed molecular networks is markedly dependent on the ligand and the coordination geometry of the metal ions. A number of multidentate organic ligands have been reported, and simple bidentate ligands with rigid linker units are particularly useful for constructing predictable and controllable coordination networks. ${ }^{27-29}$ Phenyl, acetylenyl and vinyl linkers are mainly used as rigid $\pi$-conjugated spacers that facilitate the formation of numerous coordination networks, ${ }^{30-32}$ whereas bidentate ligands containing rigid aliphatic linker units still have to be exploited systematically. ${ }^{33-36}$ In particular, adamantanebased bidentate ligands have the following unique features: (i) mechanical rigidity; (ii) well-defined conformation, making them ideal candidates for novel building blocks for the creation

† To whom correspondence should be addressed.

E-mail: kohara@kph.bunri-u.ac.jp; kyamaguchi@kph.bunri-u.ac.jp of metal-driven complexes; and (iii) coordination sites at both ends in the $V$-shaped direction. Thus, the generating of suitable orientations of the carboxyl and pyridyl groups linked to rigid adamantane spacers should lead to the formation of predictable and desired structural aggregates. We have selected imidazole and benzimidazole groups as coordination sites ${ }^{37-44}$ because a variety of imidazole- and benzimidazole-containing ligands coupled with flexible and rigid spacers were previously exploited and their coordination networks reported. In addition, the significant role of ligand backbone modification by altering the terminal groups at the coordination sites was revealed in studies concerning the influence of molecular shapes and steric hindrances for the generation of metal-organic frameworks. ${ }^{45,46}$

Although the functionalization of adamantane spacers has provided various metal-organic frameworks, the precise prediction of the direction and shape of the polymerization with multidentate organic ligands has remained a difficult problem due to the reversible coordination bond property and the diversity of the metal-ligand combinations. In addition, not enough attention has been given to complexes fabricated on the basis of the combination of several multidentate ligands and metals called as coordination oligomers. We developed coldspray ionization mass spectrometry (CSI-MS), which can ionize labile organic species and fragile complexes, such as Grignard reagents, ${ }^{47}$ self-assembling supramolecular complexes, ${ }^{48,49}$ and biomolecular aggregation species, ${ }^{50-54}$ formed via non-covalent 

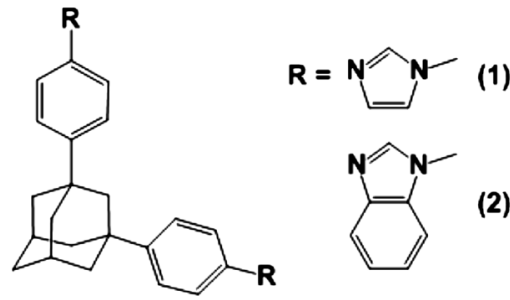

\section{Co (1a) Cd (1b) \\ Co (2a)}

Fig. 1 Adamantane-based bidentate ligands $\mathbf{1}$ and $\mathbf{2}$, and constructing respective complex by cobalt(II) and cadmium(II).

interactions. The notable feature of CSI-MS is the softness of the ionization process for a target molecule to produce a thermally unstable molecular ion involving solvent and/or the counter ions without any fragmentations. In our previous works, ${ }^{55,56}$ we focused on coordination polymers, and used CSIMS to investigate the solvent-dependent complexation of $\mathrm{CoCl}_{2}$ with adamantane-based bidentate ligands. CSI-MS revealed that the formation of coordination polymers was dependent on the methanol/chloroform ratio in solution.

In this paper, we report on the preparation and structural analysis of bidentate organic molecules $(\mathbf{1}, \mathbf{2})$ having two imidazole or benzimidazole moieties linked with a rigid 1,3-diphenyladamantane spacer, constructing the respective complexes through the cobalt(II) and cadmium(II) coordination shown in Fig. 1. The crystallographic analyses of three metalorganic frameworks of $\left[\mathrm{Co}_{2}(\mathrm{MeOH})_{2}\right]\left(\mathrm{NO}_{3}\right)_{2} \cdot \mathrm{CHCl}_{3}$ (1a) and $\left[\mathrm{Cd1}_{2}(\mathrm{MeOH})_{2}\right]\left(\mathrm{NO}_{3}\right)_{2} \cdot \mathrm{CHCl}_{3}(\mathbf{1 b})$, and $\left[\mathrm{Co}_{2}\left(\mathrm{NO}_{3}\right)_{2}\right](\mathbf{2 a})$ are shown. The polymerization process to form the three complexes was detected in the crystallization solution by CSI-MS.

\section{Experimental}

\section{General}

All reagents and solvents were obtained from commercial suppliers and used without further purification. The melting points were determined using an ATM-01. Elemental analyses were performed with a Perkin-Elmer 2400 elemental analyzer. IR spectra were recorded on a Jasco FT/IR-6300 instrument. ${ }^{1} \mathrm{H}$ and ${ }^{13} \mathrm{C}$ NMR spectra were recorded on a Bruker AV400 spectrometer at $300 \mathrm{~K}$ in $\mathrm{CDCl}_{3}$ with trimethylsilane as a reference. X-ray crystal structure data were collected using a Bruker SMART APEX II diffractometer with Mo $K \alpha$ radiation. Column chromatography was performed on a Wakogel C200, and thin-layer chromatography was carried out on 2.0-mm Merck precoated silica gel glass plates. Gel permeation chromatography was performed using recycling preparative HPLC (LC-9204, Japan Analytical Industry Co., Ltd.) and a JAIGEL H series column (Japan Analytical Industry Co., Ltd.). HRMS measurements were performed using a Fourier transform ion cyclotron resonance mass spectrometer (FT-ICR MS; ApexQe 9.4 T, Bruker Daltonics, Inc., Billerica, MA).

Cold-spray ionization mass spectrometry and MS/MS conditions

CSI-MS measurements were performed using a FT-ICR MS. The heater of the desolvation assembly in ion source was turned off and the temperature was kept at around $310 \mathrm{~K}$. The experimental conditions of cold-spray ionization were as follows: ESI needle voltage of $+4.5 \mathrm{kV}$; sheath gas flow rate, $1.0 \mathrm{~L} / \mathrm{min}$; dry gas flow rate, $5.0 \mathrm{~L} / \mathrm{min}$; sample flow rate, $120 \mu \mathrm{L} / \mathrm{h}$. Both the sheath gas and the dry gas were nitrogen gas generated by NM32LA (Peak Scientific Instruments Ltd.,
UK). In MS/MS experiments, collision-induced dissociation (CID) was adopted with argon as a collision gas. The collision gas voltage was set to $20 \mathrm{~V}$ to produce large ion peaks that are intense enough for assignment based on comparisons of the isotope patterns between calculations and observations.

\section{Crystallization of complex $\mathbf{1 a}, \mathbf{1 b}$ and $\mathbf{2 a}$}

Methanol solutions $(4.0 \mathrm{~mL})$ of $\mathrm{Co}\left(\mathrm{NO}_{3}\right)_{2} \cdot 6 \mathrm{H}_{2} \mathrm{O}$ and $\mathrm{Cd}\left(\mathrm{NO}_{3}\right)_{2} \cdot 4 \mathrm{H}_{2} \mathrm{O} \quad(0.04 \mathrm{mmol})$ were added to chloroform solutions $(8.0 \mathrm{~mL})$ of ligand $1(0.08 \mathrm{mmol})$, respectively. The solutions were stirred for several minutes. After the solutions were slowly evaporated for one week at room temperature, single crystals $\mathbf{1 a}$ and $\mathbf{1 b}$ were formed and isolated by filtration, respectively. A methanol solution $(2.0 \mathrm{~mL})$ of cobalt nitrate hydrate $(0.04 \mathrm{mmol})$ was added to a chloroform $/$ methanol solution $(5.0 \mathrm{~mL}, 4 / 1, \mathrm{v} / \mathrm{v})$ of ligand $2(0.04 \mathrm{mmol})$ and the solution was stirred for several minutes. After vapor diffusion of tetrahydrofuran into the solution for three days at room temperature, crystals of $\mathbf{2 a}$ were formed and isolated by filtration.

\section{Results and Discussion}

The synthesis of disubstituted adamantane molecule $\mathbf{1}$ was accomplished with a previously reported procedure. ${ }^{55}$ Disubstituted adamantane molecule $\mathbf{2}$ was similarly prepared from a copper(I)-catalyzed reaction of benzimidazole and 1,3-bis(4-iodophenyl)adamantane in $51 \%$ yield. Single-crystal X-ray analysis of $\left[\mathrm{Co1}_{2}(\mathrm{MeOH})_{2}\right]\left(\mathrm{NO}_{3}\right)_{2} \cdot \mathrm{CHCl}_{3} \quad$ (1a) and $\left[\mathrm{Cd}_{2}(\mathrm{MeOH})_{2}\right]\left(\mathrm{NO}_{3}\right)_{2} \cdot \mathrm{CHCl}_{3} \quad(\mathbf{1 b})$, and $\left[\mathrm{Co}_{2}\left(\mathrm{NO}_{3}\right)_{2}\right] \quad$ (2a) revealed that adamantine-based bidentate ligands $\mathbf{1}$ and $\mathbf{2}$ formed three types of complexes obtained from a mixture of chloroform and methanol. However, suitable single crystals of cadmium(II) coordinated ligands 2 were not obtained. Crystal data and selected bond lengths and angles for these three crystals are presented in Table S1 and Figs. S1-S3 (Supporting Information).

Complex 1a crystallized in the monoclinic system with the space group $C 2 / c$. X-ray crystallographic analysis revealed that complex 1a forms a 2D interpenetrating network in the crystal (Fig. 2). The Co(II) atom resides in a distorted octahedral environment with four nitrogen atoms from imidazole groups at the equatorial positions and two oxygen atoms from two methanol molecules at the apical positions $[\mathrm{Co}-\mathrm{N}=2.131(5)$ and 2.139(5) $\mathrm{A}, \mathrm{Co}-\mathrm{O}=2.129(4) \AA]$ (Fig. 2a). Bidentate ligand 1 acts as a bridge between two adjacent $\mathrm{Co}(\mathrm{II})$ centers to generate a 2D $(4,4)$ network composed of eight-membered chair-shaped macrocycles with a side of $11.3 \AA$ (measured from the center of the adamantane to the Co(II) atom) (Fig. 2b). Two pairs of 2D networks interweave in parallel to afford a two-fold interpenetrating network (Fig. 2c). The cavity in the eightmembered chair-shaped macrocycle is occupied by two chloroform molecules and four nitrate ions. Further, the 2D layered aggregates are packed directly along the $c$ axis of a unit cell (Fig. 2d). The 2D layers in the crystal display an interlayer separation of $9.37 \AA$ (measured between the plane composed of each $\mathrm{Co}(\mathrm{II})$ atoms in the $2 \mathrm{D}$ layers).

Complex $\mathbf{1 b}$ crystallized in the monoclinic system with the space group $C 2 / c$. X-ray crystallographic analysis showed a similar structure to 1a. Complex $\mathbf{1 b}$ forms a double 2D interpenetrating network (Fig. 3). The Cd(II) atom exists in a distorted octahedral environment with four nitrogen atoms from imidazole groups at the equatorial positions and two oxygen atoms from two methanol molecules at the apical positions 
(a)<smiles>COCOOP(=O)(OCOC)OOCOC</smiles>

(b)

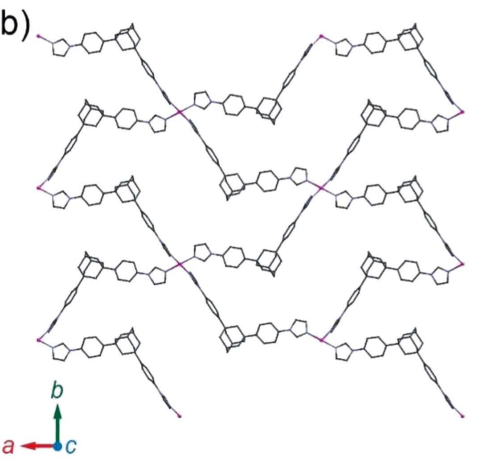

(c)

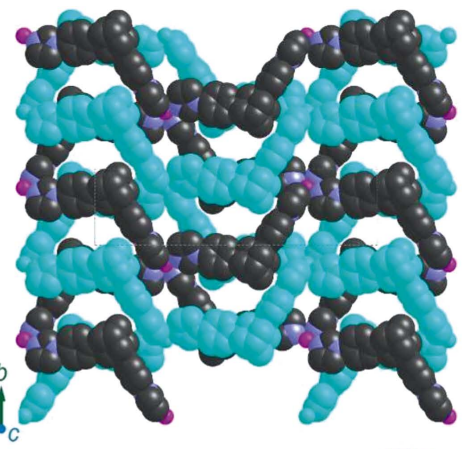

(d)

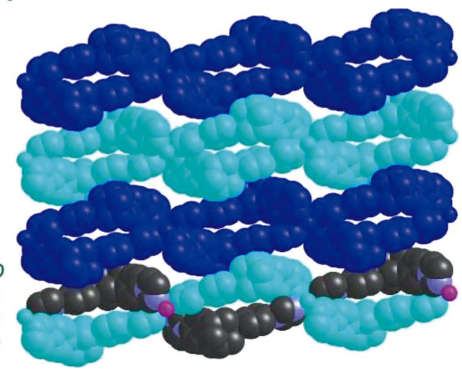

Fig. 2 Crystal structure of complex 1a. (a) Coordination environment around the Co(II) center. Coordinated solvent molecules (methanol) are indicated. (b) View of a single 2D network structure. (c) A 2D layer composed by two interpenetrating 2D nets and (d) view of the laminated layers from the direction of the $b$ axis using space-filling models. Co, Magenta; $\mathrm{C}$, black; $\mathrm{N}$, blue; $\mathrm{O}$, red for (a), (b). The hydrogen atoms, solvent molecules and counter anions are omitted for clarity in all cases.

(a)<smiles>COCOOOOP(=O)(OOC)OOOC</smiles>

(b)

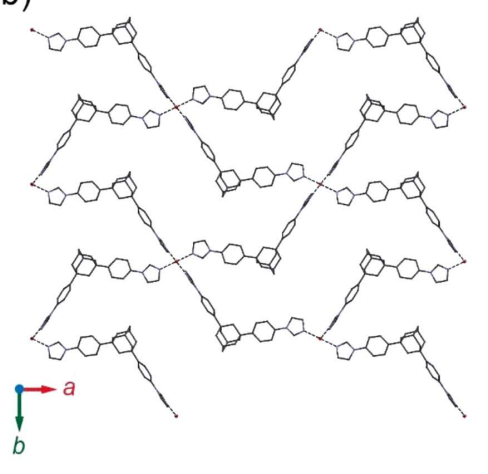

(c)
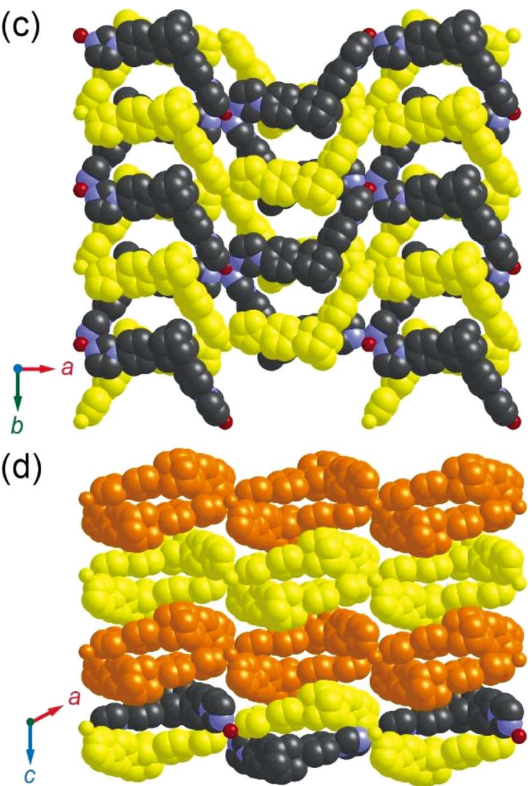

Fig. 3 Crystal structure of complex 1b. (a) Coordination environment around the $\mathrm{Cd}(\mathrm{II})$ center. Coordinated solvent molecules (methanol) are indicated. (b) View of a single 2D network structure. (c) 2D layer composed by two interpenetrating 2D nets and (d) a view of the laminated layers from the direction of the $b$ axis using space-filling models. Cd, Brown; C, black; N, blue; O, red for (a), (b). The hydrogen atoms, solvent molecules and counter anions are omitted for clarity.

$[\mathrm{Cd}-\mathrm{N}=2.284(2) \quad$ and $\quad 2.3473(19) \AA, \quad \mathrm{Cd}-\mathrm{O}=2.373(2) \AA]$ (Fig. 3a). Bidentate ligand $\mathbf{1}$ acts as a bridge between two adjacent $\mathrm{Cd}(\mathrm{II})$ centers, resulting in the generation of a $2 \mathrm{D}(4,4)$ network composed of eight-membered chair-shaped macrocycles measuring a side of $11.4 \AA$ (measured from the center of the adamantane to the $\mathrm{Cd}(\mathrm{II})$ atom) (Fig. 3b). Two pairs of 2D networks interweave in parallel to give a twofold interpenetrating structure (Fig. 3c). Two chloroform molecules and four nitrate ions are located in individual cavities. Further, the packing of the $2 \mathrm{D}$ layered structures in the crystal is realized directly along the $c$ axis (Fig. 3d). The 2D layers in the crystal display an interlayer separation of $9.15 \AA$ (measured between the plane 
(a)

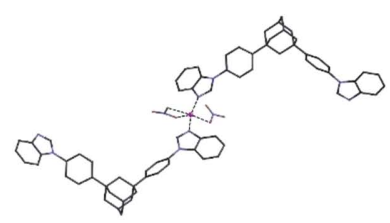

(b)

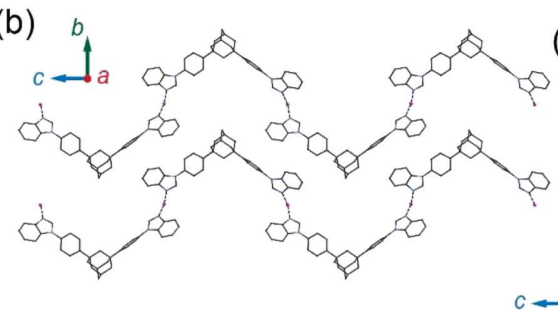

(c)

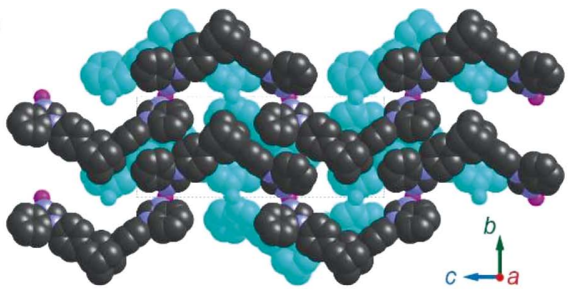

(d)

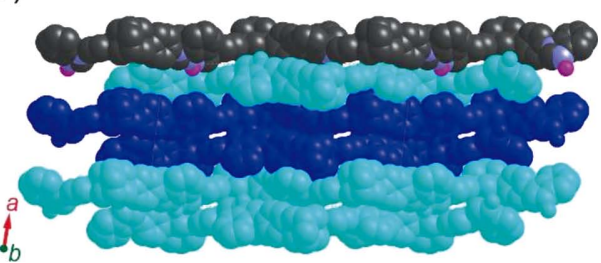

Fig. 4 Crystal structure of complex 2a. (a) Coordination environment around the Co(II) center. (b) Infinite 1D zigzag chain. (c) Top view and (d) side view of the packing structure using a space-filling model. Co, Magenta; C, black; N, blue; O, red for (a), (b). Hydrogen atoms and counter anions are omitted for clarity.

composed of each $\mathrm{Cd}(\mathrm{II})$ atoms in the 2D layers).

Complex 2a crystallized in the monoclinic system with the space group $C 2 / c$. X-ray crystallographic analysis showed that complex 2a forms a 1D zigzag structure in which ligand $\mathbf{2}$ is connected by $\mathrm{Co}(\mathrm{II})$ atoms (Fig. 4). The $\mathrm{Co}$ (II) atom exists in a five-coordinate environment with two nitrogen atoms from benzimidazole groups and three oxygen atoms from two nitrate anions $[\mathrm{Co}-\mathrm{N}=2.044(2)$ and 2.020(2) $\AA, \quad \mathrm{Co}-\mathrm{O}=2.228(15)$, 2.011(4) and 2.099(6) $\AA$ ] (Fig. 4a). Bidentate ligand 2 acts as a bridge between adjacent $\mathrm{Co}(\mathrm{II})$ centers, resulting in the generation of $1 \mathrm{D}$ zigzag chains with lengths of $21.1 \AA$ (measured from the center of one adamantane molecule to the center of another adamantane molecule) directly along the $c$ axes (Figs. 4b and 4c). Further, 1D zigzag chains are layered along the $a$ and $b$ axes of a unit cell (Fig. 4d).

CSI-MS was adopted to detect the formation of coordination polymers. In our previous work, we measured two CSI mass spectra of 1) discrete complex and 2) continuous metal and ligand adducts from different crystallization solution having the same metal-ligand ratio, but the different methanol/chloroform ratio. Similarly, the crystallization solutions of $\mathbf{1 a}, \mathbf{1} \mathbf{b}$ and $\mathbf{2 a}$ were subjected to CSI-MS and their mass spectra are shown in Figs. 5a, 5b, and 5c, respectively. In Fig. 5a, the ion peak at $\mathrm{m} / \mathrm{z}$ 421.2 was assigned to protonated ligand $1,\left([1+\mathrm{H}]^{+}\right)$. The ion peak at $\mathrm{m} / \mathrm{z} 899.4$ was derived from metal-ligand complex with 1:2 ratio. The stoichiometry of the metal-ligand 1:2 ratio was consistent with that observed in the crystal of 1a. The ion peaks at $m / z, 495.1,705.3,961.4,1354.9$ and 1747.4 were assigned to ions based on singly or doubly metal-ligand charged complexes with a few nitrate adducts. Ion identifications and peak assignments for cobalt-ligand complex $\mathbf{1}$ appear in Fig. 5a and Table 1. With the exception of ion peaks based on oxygen adducts, the intensities of the ion peaks were lower than those observed for the protonated ligand $\left([\mathbf{1}+\mathrm{H}]^{+}\right)$and the metalligand complex with 1:2 ratio $\left(\left[\mathrm{Co}_{2}\right]^{+}\right)$. As well as cobaltligand complex $\mathbf{1}$, the ion peaks assigned to cadmium-ligand complex 1 in Fig. $5 b$ and Table 2 were very similar to those observed in Fig. 5a. The ion peaks at $\mathrm{m} / \mathrm{z} 421.2$ and 1016.4 were assigned to the protonated ligand $\left([1+\mathrm{H}]^{+}\right)$and the metal-ligand complex with 1:2 ratio, $\left(\left[\mathrm{Cd} \mathbf{1}_{2}+\mathrm{A}\right]^{+}\right.$, where $\mathrm{A}$ is the nitrate anion), respectively. Other weak ion peaks were assigned on the basis of the combination of the metal and the ligand with

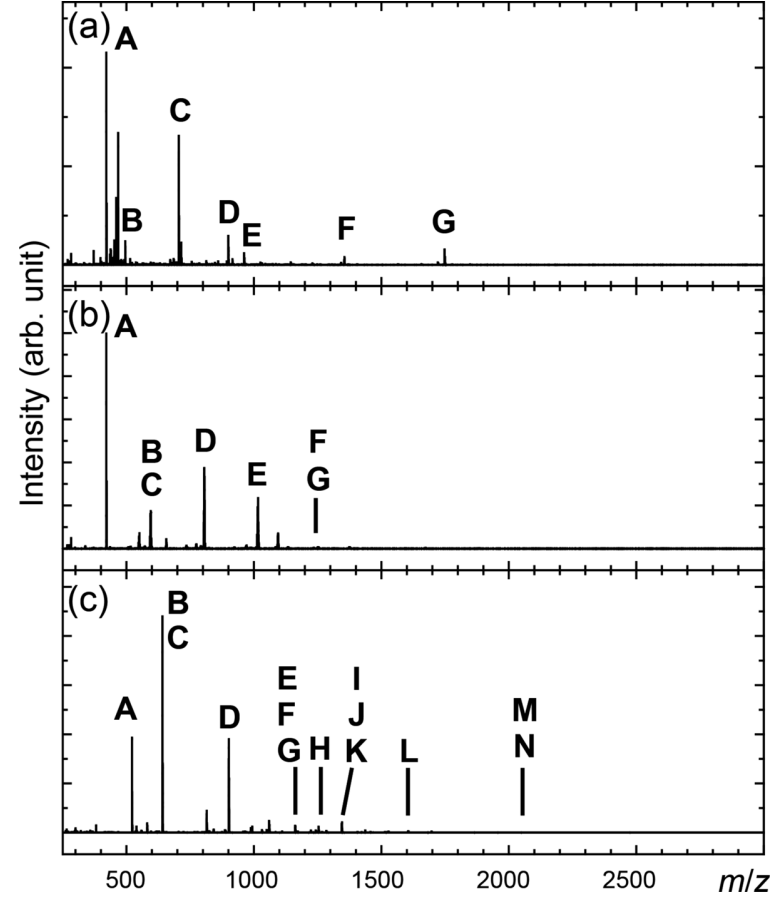

Fig. 5 CSI mass spectra of crystallization solutions for the complexation of imidazole-ligand $\mathbf{1}$ with cobalt (a), imidazole-ligand $\mathbf{1}$ with cadmium (b), and benzimidazole-ligand $\mathbf{2}$ with cobalt (c). The peak labels shown in (a), (b) and (c) correspond to the peak labels summarized in Tables 1,2 and 3, respectively.

the anion adduct. Ion identifications and peak assignments for cobalt-ligand complex $\mathbf{2}$ appear in Fig. 5c and Table 3. Interestingly, the major ion peak was assigned to the metalligand complex with a 1:1 ratio. The stoichiometry of the metal-ligand complex with 1:1 ratio was consistent with that observed in the crystal of $2 \mathbf{a}$. It was confirmed that the unique metal-ligand complex was presented in solution, which is related to the independent molecule ordered in the crystal. However, ion peaks corresponding to higher-order coordination polymers could not be clearly observed in the CSI mass spectrum. 
Table 1 Oligomeric complex ions with Co metal and ligand 1 detected using CSI-MS $\left(\mathrm{A}=\mathrm{NO}_{3}{ }^{-}\right)$

\begin{tabular}{clccc}
\hline Peak & $\begin{array}{c}\text { Chemical } \\
\text { formula with } \\
\text { charged state } \\
\text { (ion) }\end{array}$ & $\begin{array}{c}\text { Observed } \\
(\mathrm{m} / \mathrm{z})\end{array}$ & $\begin{array}{c}\text { Theoretical } \\
(\mathrm{m} / \mathrm{z})\end{array}$ & $\begin{array}{c}\text { Error, } \\
\mathrm{ppm}\end{array}$ \\
\hline $\mathrm{A}$ & {$[\mathbf{1}+\mathrm{H}]^{+}$} & 421.2389 & 421.2387 & 0.6 \\
$\mathrm{~B}$ & {$[\mathrm{Co}+\mathrm{O}+\mathbf{1}]^{+}$} & 495.1600 & 495.1590 & 2.2 \\
$\mathrm{C}$ & {$\left[\mathrm{Co}_{2} \mathbf{1}_{3}+2 \mathrm{O}\right]^{2+}$} & 705.2754 & 705.2747 & 1.0 \\
$\mathrm{D}$ & {$\left[\mathrm{Co}_{2}\right]^{+}$} & 899.3975 & 899.3955 & 2.3 \\
$\mathrm{E}$ & {$\left[\mathrm{Co}_{2} \mathrm{~A}\right]^{+}$} & 961.3856 & 961.3833 & 2.4 \\
$\mathrm{~F}$ & {$\left[\mathrm{Co}_{4} \mathbf{1}_{5} \mathrm{~A}_{6}\right]^{2+}$} & 1354.9141 & 1354.9093 & 3.5 \\
$\mathrm{G}$ & {$\left[\mathrm{Co}_{3} \mathbf{1}_{3} \mathrm{~A}_{5}\right]^{+}$} & 1747.4414 & 1747.4323 & 5.2 \\
\hline
\end{tabular}

The peak labels correspond to the labels of the ion peaks shown in Fig. 5(a).

Table 2 Oligomeric complex ions with $\mathrm{Cd}$ metal and ligand $\mathbf{1}$ detected using CSI-MS $\left(\mathrm{A}=\mathrm{NO}_{3}^{-}\right)$

\begin{tabular}{clrrr}
\hline Peak & $\begin{array}{c}\text { Chemical } \\
\text { formula with } \\
\text { charged state } \\
\text { (ion) }\end{array}$ & $\begin{array}{c}\text { Observed } \\
(\mathrm{m} / \mathrm{z})\end{array}$ & $\begin{array}{c}\text { Theoretical } \\
(\mathrm{m} / \mathrm{z})\end{array}$ & $\begin{array}{c}\text { Error, } \\
\mathrm{ppm}\end{array}$ \\
\hline $\mathrm{A}$ & {$[\mathbf{1}+\mathrm{H}]^{+}$} & 421.2390 & 421.2387 & 0.7 \\
$\mathrm{~B}$ & {$[\mathrm{Cd} \mathbf{A}]^{+}$} & 596.1236 & 596.1227 & 1.6 \\
$\mathrm{C}$ & {$\left[(\mathrm{Cd} \mathbf{A})_{2}\right]^{2+}$} & 594.6243 & 594.6225 & 3.1 \\
$\mathrm{D}$ & {$\left[\mathrm{Cd} \mathbf{1}_{3} \mathrm{~A}_{2}\right]^{2+}$} & 805.2401 & 805.2391 & 1.2 \\
E & {$\left[\mathrm{Cd} \mathbf{1}_{2} \mathrm{~A}\right]^{+}$} & 1016.3592 & 1016.3550 & 4.1 \\
$\mathrm{~F}$ & {$\left[\mathrm{Cd}_{2} \mathbf{1}_{2} \mathrm{~A}_{3}\right]^{+}$} & 1252.2414 & 1252.2343 & 5.7 \\
$\mathrm{G}$ & {$\left[\left(\mathrm{Cd}_{2} \mathbf{1}_{2} \mathrm{~A}_{3}\right)^{2}\right]^{2+}$} & 1251.7427 & 1251.7345 & 6.6 \\
\hline
\end{tabular}

The peak labels correspond to the labels of the ion peaks shown in Fig. 5(b).

The ionization efficiency in CSI-MS was low compared to that in the ESI method, due to solvent addition at low temperature, and fragile complexes were decomposed in ESI measurement.

We then determined whether higher-order coordination oligomers are present or not in the crystallization solution by CSI-MS/MS. Surprisingly, the ion peaks of $\left[\mathrm{M}_{3} \mathrm{~L}_{3} \mathrm{~A}_{5}\right]^{+}$(where, $\mathrm{M}$ is metal, $\mathrm{L}$ is ligand, $\mathrm{A}$ is the nitrate anion) appeared by collision induced dissociation (CID) of the crystals of $\mathbf{1 a}, \mathbf{1 b}$ and $2 \mathbf{a}$ as shown in Figs. $6 \mathrm{a}, 6 \mathrm{~b}$, and $6 \mathrm{c}$, respectively. The intensities of ion peaks larger than $\mathrm{m} / \mathrm{z} 1500$ were also increased in the CSI-MS/MS CID spectra of $\mathbf{1 b}$ and 2a. Peak assignments are given in Tables S2, S3, and S4 (Supporting Information), for 1a, $1 \mathbf{b}$ and 2a, respectively. Ion peaks of interesting coordination oligomers were observed under the MS/MS condition, but not in the original CSI mass spectra, although a metal-ligand complex with $1: 1$ or $1: 2$ ratio could be stably ionized. From these observations, we confirmed the presence of the soluble oligomers in solution, which are related to part of the coordination polymer or the independent molecules ordered in the crystal.

\section{Conclusions}

In conclusion, we have demonstrated that adamantane-based bidentate ligands bearing imidazole and benzimidazole moieties are versatile building blocks for the construction of coordination polymers and networks. The complexation of bidentate ligands $(\mathbf{1}, \mathbf{2})$ and two transition metals in a mixture of chloroform and
Table 3 Oligomeric complex ions with Co metal and ligand 2 detected using CSI-MS $\left(\mathrm{A}=\mathrm{NO}_{3}^{-}\right)$

\begin{tabular}{clccc}
\hline Peak & $\begin{array}{c}\text { Chemical } \\
\text { formula with } \\
\text { charged state } \\
\text { (ion) }\end{array}$ & $\begin{array}{c}\text { Observed } \\
(\mathrm{m} / \mathrm{z})\end{array}$ & $\begin{array}{c}\text { Theoretical } \\
(\mathrm{m} / \mathrm{z})\end{array}$ & $\begin{array}{c}\text { Error, } \\
\text { ppm }\end{array}$ \\
\hline $\mathrm{A}$ & {$[\mathbf{2}+\mathrm{H}]^{+}$} & 521.2702 & 521.2700 & 0.5 \\
$\mathrm{~B}$ & {$[\mathrm{Co} 2 \mathrm{~A}]^{+}$} & 641.1833 & 641.1832 & 0.3 \\
$\mathrm{C}$ & {$\left[(\mathrm{Co} 2 \mathrm{~A})_{2}\right]^{2+}$} & - & 641.1817 & - \\
$\mathrm{D}$ & {$\left[\mathrm{Co}_{2} \mathbf{2}_{3} \mathrm{~A}_{2}\right]^{2+}$} & 901.8171 & 901.8161 & 1.1 \\
$\mathrm{E}$ & {$\left[\mathrm{Co} \mathbf{2}_{2} \mathrm{~A}\right]^{+}$} & 1161.4484 & 1161.4460 & 2.1 \\
$\mathrm{~F}$ & {$\left[\left(\mathrm{Co} \mathbf{2}_{2} \mathrm{~A}\right)_{2}\right]^{2+}$} & 1161.9498 & 1161.4947 & 2.0 \\
$\mathrm{G}$ & {$\left[\left(\mathrm{Co} \mathbf{2}_{2} \mathrm{~A}\right)_{3}\right]^{3+}$} & 1162.1171 & 1162.1146 & 2.2 \\
$\mathrm{H}$ & {$\left[\mathrm{Co}_{3} \mathbf{2}_{4} \mathrm{~A}_{4}\right]^{2+}$} & 1253.4045 & 1253.4018 & 2.1 \\
$\mathrm{I}$ & {$\left[\mathrm{Co}_{2} \mathbf{2}_{2} \mathrm{~A}_{3}\right]^{+}$} & 1344.3578 & 1344.3547 & 2.3 \\
$\mathrm{~J}$ & {$\left[\left(\mathrm{Co}_{2} \mathbf{2}_{2} \mathrm{~A}_{3}\right)_{2}\right]^{2+}$} & 1344.8593 & 1344.8562 & 2.3 \\
$\mathrm{~K}$ & {$\left[\left(\mathrm{Co}_{2} \mathbf{2}_{2} \mathrm{~A}_{3}\right)_{2}\right]^{3+}$} & 1345.0262 & 1345.0234 & 2.1 \\
$\mathrm{~L}$ & {$\left[\mathrm{Co}_{4} \mathbf{2}_{5} \mathrm{~A}_{6}\right]^{2+}$} & 1605.4933 & 1605.4893 & 2.4 \\
$\mathrm{M}$ & {$\left[\mathrm{Co}_{3} \mathbf{2}_{3} \mathrm{~A}_{5}\right]^{+}$} & 2048.5350 & 2048.5293 & 2.8 \\
$\mathrm{~N}$ & {$\left[\left(\mathrm{Co}_{3} \mathbf{2}_{3} \mathrm{~A}_{5}\right)_{2}\right]^{2+}$} & - & 2048.5293 & - \\
\hline
\end{tabular}

The peak labels correspond to the labels of the ion peaks shown in Fig. 5(c).

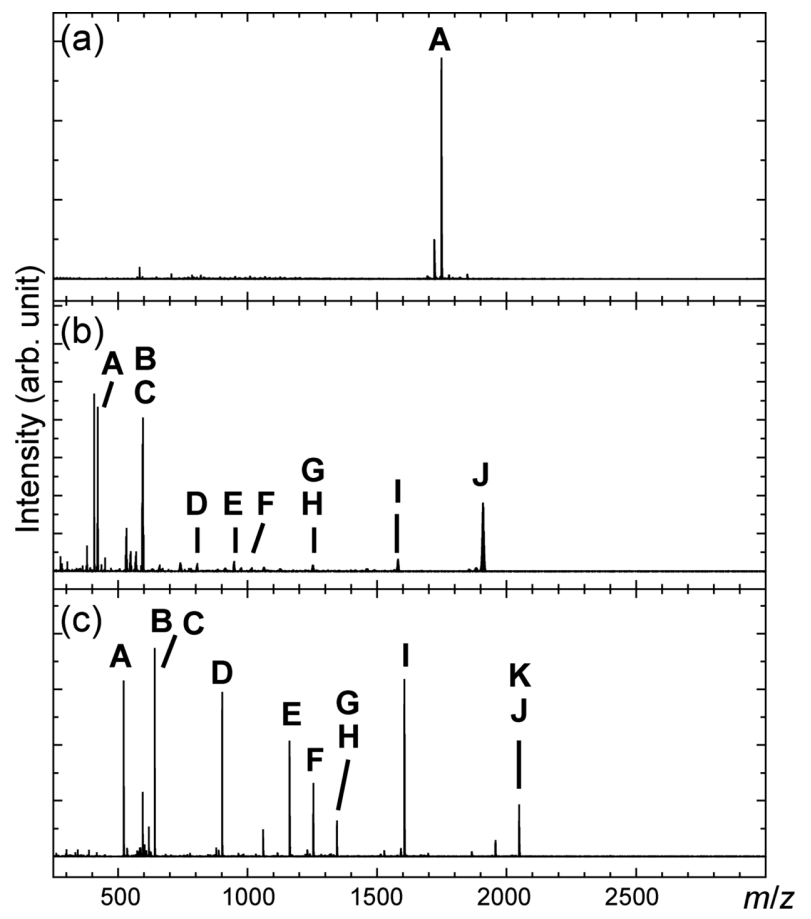

Fig. 6 CSI-MS/MS CID spectra of a crystallization solution for the complexation of imidazole-ligand 1 with cobalt (a), imidazole-ligand 1 with cadmium (b), and benzimidazole-ligand $\mathbf{2}$ with cobalt (c). The peak labels shown in (a), (b) and (c) correspond to the peak labels summarized in Tables S2, S3 and S4, respectively.

methanol gave corresponding complexes 1a, 1b and 2a. Despite the use of different metal ions, complexes $\mathbf{1 a}$ and $\mathbf{1 b}$ formed similar doubly interpenetrated continuous $2 \mathrm{D}$ sheets. In contrast to complex 1a, complex 2a formed 1D zigzag chains, indicating that modifying the terminal groups in the bidentate ligand affects the formation of metal-mediated structures, due to a steric hindrance and metal-coordinating ability. CSI-MS and MS/MS clarified the presence of metal-ligand complex 
corresponding to the simplest repeating unit in a crystal and coordination oligomers in solution. Studies on the formation of other diverse coordination polymers from tri- and tetradentate adamantane-based ligands bearing functional groups as coordination sites and the control of their polymerization by CSI-MS and MS/MS are under way.

\section{Acknowledgements}

This work was supported by a Grant-in-Aid for Young Scientists (B) (number 25860033) from JSPS KAKENHI.

\section{Supporting Information}

The crystallographic data, crystallographic information files (CIF), ligand characterization and additional assignment table of CSI-MS/MS are available. This material is available free of charge on the Web at http://www.jsac.or.jp/analsci/.

\section{References}

1. M. Kawano and M. Fujita, Coord. Chem. Rev., 2007, 251, 2592.

2. A. M. Spokoyny, D. Kim, A. Sumrein, and C. A. Mirkin, Chem. Soc. Rev., 2009, 38, 1218.

3. J. J. Perry IV, J. A. Perman, and M. J. Zaworotko, Chem. Soc. Rev., 2009, 38, 1400.

4. A. Phan, C. J. Doonan, F. J. Uribe-romo, C. B. Knobler, M O. Keeffe, and O. M. Yaghi, Acc. Chem. Res., 2010, 43, 58

5. J. R. Holst and A. I. Cooper, Adv. Mater, 2010, 22, 5212.

6. S. Hasegawa, S. Horike, R. Matsuda, S. Furukawa, K. Mochizuki, Y. Kinoshita, and S. Kitagawa, J. Am. Chem. Soc., 2007, 129, 2607.

7. J. Lee, O. K. Farha, J. Roberts, K. A. Scheidt, S. T. Nguyen, and J. T. Hupp, Chem. Soc. Rev., 2009, 38, 1450.

8. H. Kim and M. P. Suh, Inorg. Chem., 2005, 44, 810.

9. W.-L. Meng, G.-X. Liu, T. Okamura, H. Kawaguchi, Z.-H. Zhang, W.-Y. Sun, and N. Ueyama, Cryst. Growth Des., 2006, 6, 2092.

10. P. Byrne, G. O. Lloyd, N. Clarke, and J. W. Steed, Angew. Chem. Int. Ed., 2008, 47, 5761.

11. D. B. Cordes and L. R. Hanton, Inorg. Chem., 2007, 46, 1634

12. S. Bureekaew, S. Horike, M. Higuchi, M. Mizuno, T. Kawamura, D. Tanaka, N. Yanai, and S. Kitagawa, Nat. Mater, 2009, 8, 831.

13. M. Kurmoo, Chem. Soc. Rev., 2009, 38, 1353.

14. Y. Inokuma, T. Arai, and M. Fujita, Nat. Chem., 2010, 2, 780.

15. D. Liu, J. P. Lang, and B. F. Abrahams, J. Am. Chem. Soc., 2011, 133, 11042.

16. Y. Inokuma, M. Kawano, and M. Fujita, Nat. Chem., 2011, 3, 349.

17. B.-C. Tzeng, T.-H. Chiu, B.-S. Chen, and G.-H. Lee, Chem. Eur. J., 2008, 14, 5237.

18. M. D. Allendorf, C. A. Bauer, R. K. Bhakta, and R. J. T. Houk, Chem. Soc. Rev., 2009, 38, 1330.

19. F. Zeng, J. Ni, Q. Wang, Y. Ding, S. W. Ng, W. Zhu, and Y. Xie, Cryst. Growth Des., 2010, 10, 1611.

20. M. Eddaoudi, J. Kim, N. Rosi, D. Vodak, J. Wachter, M. O'Keeffe, and O. M. Yaghi, Science, 2002, 295, 469.

21. S. Henke and R. A. Fischer, J. Am. Chem. Soc., 2011, 133, 2064.

22. J.-R. Li, R. J. Kuppler, and H.-C. Zhou, Chem. Soc. Rev., 2009, 38, 1477.

23. L. J. Murray, M. Dincă, and J. R. Long, Chem. Soc. Rev., 2009, 38, 1294.

24. N. L. Rosi, J. Eckert, M. Eddaoudi, D. T. Vodak, J. Kim, M.
O'Keeffe, and O. M. Yaghi, Science, 2003, 300, 1127.

25. J. L. C. Rowsell and O. M. Yaghi, Angew. Chem. Int. Ed., 2005, 44, 4670.

26. S. Shimomura, M. Higuchi, R. Matsuda, K. Yoneda, Y. Hijikata, Y. Kubota, Y. Mita, J. Kim, M. Takata, and S. Kitagawa, Nat. Chem., 2010, 2, 633.

27. K. I. Nättinen and K. Rissanen, Cryst. Growth Des., 2003, $3,339$.

28. Y.-H. Li, C.-Y. Su, A. M. Goforth, K. D. Shimizu, K. D. Gray, M. D. Smith, and H.-C. zur Loye, Chem. Commun., 2003, 1630 .

29. M. Fujita, M. Tominaga, A. Hori, and B. Therrien, Acc. Chem. Res., 2005, 38, 369.

30. K. Biradha and M. Fujita, Chem. Commun., 2002, 1866.

31. O.-S. Jung, S. H. Park, K. M. Kim, and H. G. Jang, Inorg. Chem., 1998, 37, 5781.

32. A. C. Sudik, A. R. Millward, N. W. Ockwig, A. P. Côté, J. Kim, and O. M. Yaghi, J. Am. Chem. Soc., 2005, 127, 7110.

33. D. J. Hoffart, S. A. Dalrymple, and G. K. H. Shimizu, Inorg. Chem., 2005, 44, 8868.

34. J.-C. Jin, Y.-Y. Wang, W.-H. Zhang, A. S. Lermontov, E. K. Lermontova, and Q.-Z. Shi, Dalton Trans., 2009, 10181.

35. J. Zhang, S. Chen, R. A. Nieto, T. Wu, P. Feng, and X. Bu, Angew. Chem. Int. Ed., 2010, 49, 1267.

36. J.-C. Jin, Y.-Y. Wang, P. Liu, R.-T. Liu, C. Ren, and Q.-Z. Shi, Cryst. Growth Des., 2010, 10, 2029.

37. J. Fan, L. Gan, H. Kawaguchi, W.-Y. Sun, K.-B. Yu, and W.-X. Tang, Chem. Eur. J., 2003, 9, 3965.

38. J. Fan and B. E. Hanson, Inorg. Chem., 2005, 44, 6998

39. J. Fan, M.-H. Shu, T. Okamura, Y.-Z. Li, W.-Y. Sun, W.-X. Tang, and N. Ueyama, New J. Chem., 2003, 27, 1307.

40. J. Fan, W. Sun, T. Okamura, W. Tang, and N. Ueyama, Inorg. Chem., 2003, 42, 3168.

41. Y. Liu, Y. Qi, Y.-Y. Lv, Y.-X. Che, and J.-M. Zheng, Cryst. Growth Des., 2009, 9, 4797.

42. J. Yang, J.-F. Ma, S. R. Batten, and Z.-M. Su, Chem. Commun., 2008, 2233.

43. L. Zhang, Y.-L. Yao, Y.-X. Che, and J.-M. Zheng, Cryst. Growth Des., 2010, 10, 528.

44. S.-R. Zheng, Q.-Y. Yang, Y.-R. Liu, J.-Y. Zhang, Y.-X. Tong, C.-Y. Zhao, and C.-Y. Su, Chem. Commun., 2008, 356.

45. Z.-X. Li, Y. Xu, Y. Zuo, L. Li, Q. Pan, T.-L. Hu, and X.-H Bu, Cryst. Growth Des., 2009, 9, 3904.

46. Z.-X. Li, T.-L. Hu, M. Hong, Y.-F. Zeng, C.-J. Li, M.-L. Tong, and X.-H. Bu, Cryst. Growth Des., 2010, 10, 1138.

47. S. Sakamoto, T. Imamoto, and K. Yamaguchi, Org. Lett., 2001, 3, 1793.

48. M. Fujita, D. Oguro, M. Miyazawa, H. Oka, K. Yamaguchi, and K. Ogura, Nature, 1995, 378, 469.

49. S. Sakamoto, M. Yoshizawa, T. Kusukawa, M. Fujita, and K. Yamaguchi, Org. Lett., 2001, 3, 1601.

50. M. Kunimura, S. Sakamoto, and K. Yamaguchi, Org. Lett., 2002, 4, 347

51. S. Sakamoto, K. Nakatani, I. Saito, and K. Yamaguchi, Chem. Commun., 2003, 788.

52. S. Sakamoto and K. Yamaguchi, Angew. Chem. Int. Ed., 2003, 42, 905.

53. F. Ibukuro, M. Fujita, K. Yamaguchi, and J.-P. Sauvage, $J$. Am. Chem. Soc., 1999, 121, 11014.

54. Y. Yamanoi, Y. Sakamoto, T. Kusukawa, M. Fujita, S. Sakamoto, and K. Yamaguchi, J. Am. Chem. Soc., 2001, 123, 980 .

55. K. Ohara, M. Tominaga, I. Azumaya, and K. Yamaguchi, Anal. Sci., 2013, 29, 773.

56. K. Ohara and K. Yamaguchi, Anal. Sci., 2012, 28, 635. 